\title{
Voluntary Environmental Regulations and Firm Innovation in China
}

\author{
Shaojie Zhang \\ Zhongnan University of Economics and Law, Wuhan, China. \\ Email:shaojie.zhang@wku.edu
}

\begin{abstract}
The world is fighting the issue of increasing levels of pollution and the detrimental effects of the ecological imprints of the business industry. Pollution and other environmental issues are causing the environment to deteriorate; however, this has also led to an increased interest in the protection of the environment. The Porter hypothesis has stimulated a long debate on whether organizational regulations can lead to changes in a firm's innovation. Building on these theories, this study evaluates the effect of voluntary environmental regulations (VERs) on the innovation of Chinese firms. For this purpose, the study uses a dichotomous dependent variable. The proxy variables used for evaluating the innovative performance of firms are the average investments made for research and development $(\mathrm{R} \& \mathrm{D})$ activities, which are evaluated on the basis of investments made and the decision to invest in innovation activities. VERs were evaluated using applications for the ISO 14000 certification. The study uses firm level variables to answer the research questions, as well as control variables such as firm size, profitability, degree of competition, and high technology industry. The results of the estimations reveal that the impact of environmental regulations (ERs) is positive and significant in terms of the innovation output of the firms under consideration. Moreover, the results also highlight the fact that large firms with high levels of profitability and a presence in the technology sector are more adept at introducing innovative activities. The study also provides some policy implications.
\end{abstract}

Keywords: GMM; POLS; Environmental Regulations; Innovation.

Citation | Shaojie Zhang (2020). Voluntary Environmental Regulations and Firm Innovation in China. Asian Journal of Economics and Empirical Research, 7(2): 171-177.

History:

Received: 14 May 2020

Revised: 19 June 2020

Accepted: 21 July 2020

Published: 17 August 2020

Licensed: This work is licensed under a Creative Common

Attribution 3.0 License (co)

Publisher: Asian Online Journal Publishing Group
Funding: This study received no specific financial support.

Competing Interests: The author declares that there are no conflicts of interests regarding the publication of this paper.

Transparency: The author confirms that the manuscript is an honest, accurate, and transparent account of the study was reported; that no vital features of the study have been omitted; and that any discrepancies from the study as planned have been explained.

Ethical: This study follows all ethical practices during writing.

\section{Contents}

1. Research Background....

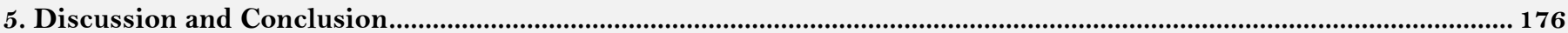

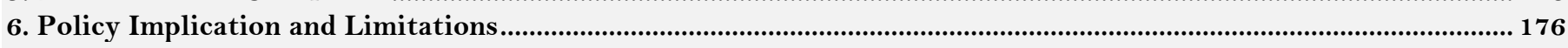

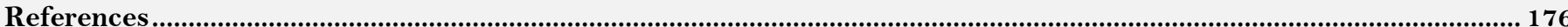




\section{Contribution of this paper to the literature}

This study contributes to existing literature by analyzing the overall impact of VERs on the FI performance and presentation in the case of China.

\section{Research Background}

A well-designed set of environmental regulations (ERs) leads to the stimulation of innovative activities (Wang \& Shen, 2016). Chinese organizations with well-designed ERs are able to use innovative technology, techniques, and tools to reduce their costs. There is a lack of competitive advantage in Chinese firms where the incorporation of such regulations has not taken place (Wang, Wu, \& Zhang, 2018). The voluntary commitments of an organization are generally voluntary ERs (VERs) that help to control pollution and conduct other activities that are concerned with protecting the environment. These ERs result in increased costs for the regulators and organizations, and they are limited due to the conflict between pollution and the development of the economy. The impact of ERs on firm innovation (FI) varies according to the environment and marketplace.

The phenomenon of innovation and ER has been gaining considerable positive attention from academic experts and scholars over the past few decades (You, Zhang, \& Yuan, 2019). However, it can be said that, even now, business performance is influenced by innovation gaps and other limitations. The number of firms operating successful business practices (Jiang, Wang, \& Li, 2018); Pan, Ai, Li, Pan, and Yan (2019) suggest that, in order to address limitations and performance gaps, a firm's context and other factors affecting innovation performance need to be evaluated and examined in detail. Studies on FI performance and related concepts are sparse and limited, which is why research efforts need to be conducted on developing firms and organizations (Liu, Li, \& Yin, 2018); Soto-Acosta, Popa, and Palacios-Marqués, 2017), in order to test the impact of social factors, Zehir and Özsahin (2008); Zehir and Özsahin (2008); Zehir and Özşahin (2008) and analyze the impact of environmental factors on FI performance and presentation. Naranjo-Gil (2009) completed research on synthesized and empirically evaluated experiences and outcomes of ERs, proposing further investigation and evaluation into these factors and variables through cross-nation and single-nation analysis. Thus, the forecasting of environmental restrictions and rules from the perspective of FI is significant.

This research has profound and constructive benefits in practice, as well as in theory. Theoretically, the results and findings of this research contribute to the current body of data and information on the above variables through an evaluation of the underlying process of identifying the impact of VERs on FI performance. Practically, the outcomes of the current paper prove to be beneficial for academic experts and practitioners, as well as the policymakers who promote and design supportive frameworks for businesses and firms in China. This paper also contributes to the Porter hypothesis by supporting analysis on whether or not VER has a favorable impact on FI and overall operational performance.

Based on the above discussion, the current study has the following aims:

- To analyze the overall impact of VERs on the FI performance and presentation, primarily based on an organizational level survey concerning ISO certification and rules in China.

- To understand and evaluate the relationship between VER and FI through Porter's hypothesis, which is entirely based on whether or not environmental rules and regulations can effectively influence organizational innovation.

The rest of the paper is organized as follows: In the second section, a detailed and supportive review of the literature is presented; the third section provides the related hypotheses; the fourth section presents the collected data and the methods used to collect data from different firms and organizations; the fifth section reports all results and the robustness evaluation; and finally, the sixth section summarizes the study's outcomes and limitations, as well as highlighting future study directions.

\section{Literature Review}

It has been postulated that strict and exacting ERs and rules can play a direct role in inducing efficiency and encouraging innovative practices that help organizations to improve and enhance their commercial competitiveness (Lanoie, Patry, \& Lajeunesse, 2008). This hypothesis was originally formulated in 1995 by Michael Porter, a famous economist who studied the environmental performance of firms (Ambec, Cohen, Elgie, \& Lanoie, 2013). According to Rubashkina, Galeotti, and Verdolini (2015), this hypothesis strongly suggested that harsh ERs and restrictions trigger the discovery and introduction of cleaner and more environmentally friendly technologies, technological procedures, and environmental enhancements. The overall effect on innovation, through the development of production processes, is that goods delivered by firms are more efficient and the firms themselves have a more innovative performance (Murty \& Kumar, 2003). Furthermore, the cost savings that can be made are essential to overcompensate for the innovation and compliance costs that are produced by new rules and regulations. As an initial benefit, firms can exploit their innovation and its related activities by learning about curve impacts or patenting, in order to achieve a leading and significant competitive image, compared to firms in nations where ER and restrictions were enforced much later. This hypothesis has been applied to various studies and research; according to Ambec and Barla (2002), firms that adopt a cost leadership strategy and have a relatively small product and goods portfolio will fare better than firms that compete over brand differentiation that have a significant number of chemicals that require ER (Rennings \& Rammer, 2011). In light of this hypothesis, several studies and research papers found that stricter and harsher ER stimulates innovation that directly affects a firm's overall innovation (Rexhäuser \& Rammer, 2014). There have been mixed results with regard to whether stricter rules improve a firm's business and whether regulations on market-based concepts, such as needs and prohibitions, have a direct impact. Moreover, economic and business theories or models recommend that market-based strategies could be more effective and significant, although different suggestions and evidence exist. For example, research on OECD nations showed no evidence that a tightening of environmental rules and policy has a permanent impact on productivity, regardless of the extent of rules. After considering the empirical proof provided in the above 
hypothesis, it can be concluded that stricter ERs can have a direct and significant influence on the innovative processes and activities carried by the firm.

Conventional ER and laws that are often described as command and management regulations play a significant role in managing and minimizing pollution (Jiang et al., 2018). However, critics argue that conventional ERs enhance the overall expenses of both organizations and regulators (Bu., Qiao, \& Liu, 2020). On the one hand, the capability and willingness of local governments to enforce ER are being questioned, as ER and policies play a role in major disputes between economic growth and environmental deterioration. For the moment, the overall execution of ERs and policies is often influenced by exploitation and corruption. On the other hand, some organizations who have undertaken these regulations have, to a degree, bypassed governmental ERs in order to reduce their costs. When this proves to be a challenge, organizations and small businesses spend more on emission minimization and pollution management. Consequently, organizations have to minimize their budgets for other processes, such as the production of goods and other management practices. Typically, it tends to be the largely innovative processes that are prominent in this technique (Ren, Li, Yuan, Li, \& Chen, 2018). Conventional ERs may lead to an insignificant level of efficiency and hinder the firm's innovative processes and strategies, which could lead to long-term consequences (Zhuge, Freeman, \& Higgins, 2020). Moreover, according to Demirel, Iatridis, and Kesidou (2018), conventional ER and other policies are part of a collective process that consists of rules to protect the environment in the region or country (Fang, Liu, \& Gao, 2019). One set of regulations have a direct impact on environmental legal issues, which mainly focus on the management of certain natural resources, such as minerals, fisheries, and forests. Although other aspects, such as the environmental influence assessment, may not fit perfectly into either category, they are nonetheless significant aspects of the ERs that directly affect FI performance. According to Feng and Chen (2018), air quality regulations are a fundamental component of ERs which govern the air pollutants emitted into the atmosphere by different firms. As described by Ball, Burt, De Vries, and MacEachern (2018), a specialized subset of air quality regulation controls the air quality in cities and residential areas. Air quality regulations are typically designed and developed to protect the health of individuals by limiting and/or eliminating pollutants emitted by firms. Several other initiatives have been developed to respond to broader environmental issues, such as limitations on chemicals used by firms in processes that directly affect the ozone layer and the creation of emissions trading programs to respond to climate change. Regulatory processes predominantly include determining and categorizing air pollutant factors, in order to limit firms' emission levels by incorporating innovative steps and dictating suitable modifications and innovative technologies. Water quality regulations are another important component of ER, as they control the release of pollutants by firms into water resources, including surface water, water stores, and groundwater (Zhou \& Feng, 2017). Efforts to regulate water quality may include determining and categorizing water pollutants released by different firms, dictating suitable pollutant concentrations in water resources, and limiting pollutant emissions from firms. Chemical safety regulations are another type of ER that governs the use of chemicals, particularly man-made chemicals in modern applications and innovative practices (Wibisana. \& Dewaranu, 2017). In contrast with media-oriented ERs, chemical management regulations seek to control the potential pollutants themselves; such regulatory efforts generally include banning certain chemicals in consumer goods and regulating certain chemicals used by firms in their processes.

In order to overcome the drawbacks of conventional ERs, Cohen and Tubb (2018) have suggested that a suitable ER framework would encourage and prompt innovation, thereby enhancing the overall competitiveness of the firm. SC Filho, Romano, De Almeida, and Sousa-Aguiar (2019) further demonstrate the fact that a suitable framework of ERs can prompt innovation and offset certain compliance expenditures. This is generally referred to as the innovation or modernization offset impact.

\subsection{Literature Review for China}

China is in the process of economic development. However, it has been observed that China's GDP growth has declined in recent years. China's consumption of energy and environmental pollution has played a critical role in this trend. During the years between 1978-2011, the usage and consumption of energy sources were continually and considerably increasing in China; at the same time, the GDP growth of China also increased (Guohui \& Yunfeng, 2012). The major reason behind this increase in GDP was China's energy usage. Based on such positive and encouraging results, China placed an emphasis on controlling environmental pollution by introducing certain rules and regulations with regard to the environment. The initial methodology employed was the introduction of control procedures, such as policies that determine the standard of emissions. However, these policies proved ineffective at the time, as they led to greater costs and lower profits. After the failure of such policies, the government of China introduced policies related to the market (Holz, 2014; Zhao, Zhao, Zeng, \& Zhang, 2015). Some examples include the "Regulation Enforcement of Export Companies' Environmental Protection", the "National Environmental Protection '12 ${ }^{\text {th }}$ Five-year' Plan”, and the "Environment Quality Standard”.

\section{Methodology}

This study is being carried out in order to evaluate the performance of organizations and their response to VERs. Data were collected to evaluate the corporate social responsibility (CSR) practices of Chinese organizations. The study used a CSR survey developed in 2006 that characterized the performance of 1268 Chinese enterprises and considered their annual reviews, which contain financial data from large organizations, as selected by the National Bureau of Statistics (NBS) of China. A total of twelve cities were chosen for the study and the application of a random sampling technique resulted in a total 120 firms from each city being selected for the study. The cities were selected on the basis of their development and other geographical constraints. The selected cities are Beijing, Changchun, Zibo, Hangzhou, Chongqing, Shijiazhuang, Dandong, Shunde, Chifeng, Shiyan, Xi'an, and Wujiang. The sample was subjected to preliminary analysis in order to detect missing values and outliers. After the removal of outliers, the final sample consisted of an unbalanced panel of 1040 firms during the period 2001-2008.

The main outcome variable in this study was the innovation of the firm. For this purpose, a dichotomous variable was designed. The first proxy variable used to evaluate the innovation of firms was the average investment 
made for research and development $(\mathrm{R} \& \mathrm{D})$ activities. This variable is referred to as ARD and is defined as the ratio of total expenditures made for R\&D in one financial year to the firm's sales income. In cases where an investment for innovation or R\&D was made during a given year, the variable assumed the value of 0 . The second variable designed to evaluate innovative input activities of organizations was a dummy variable, DRD. This variable was used to evaluate the organizations' decision on whether or not to make an R\&D investment. In cases where an investment is made, this variable assumed the value of 1 ; if not, it assumed the value of 0 .

The key explanatory variable in this study was the ISO 14000 certification. A dummy variable was designed to evaluate the impact of voluntary regulation on firms when they have registered for or attained an ISO certification. The measures of the certification were expected to have a significant impact on the evaluation of innovation activities of the organizations. In cases in which the organization has the certification, the variable assumed the value of 1 .

The study also introduced key control variables in order to accurately evaluate the extent of innovation and voluntary regulations. The control variables were used to evaluate features of the organizations that were under consideration. One of the evaluated characteristics was organization size, which was defined as the logarithm of the total number of people employed. Previous literature has not evaluated the impact of organizational size on innovative activities (Becheikh, Landry, \& Amara, 2006; Stock., Greis, \& Fischer, 2002). The profit of the organization is also evaluated, which was defined as the ratio of annual profit before taxation to revenue generated by sales. This variable was anticipated to have a positive impact on the innovation of firms because there is evidence to suggest a close relationship between firm profitability and innovation (Ukpabio, Siyanbola, \& Studies, 2017). The competition of firms was also evaluated using the dummy variables of low and high. These variables assumed the value of 1 in cases in which a firm's premium product line faces market competition, whether it be low or high; if not, a value of o was assumed. Theoretically, innovation is more probable in organizations that are characterized by high levels of technology. Therefore, a dummy variable measuring whether or not the firm belongs to a high technology industry was also introduced in the study (Verdu, Tamayo, \& Ruiz-Moreno, 2012).

The primary aim of this study was to evaluate whether VERs impact the advancement of innovation in firms. For this purpose, the following model has been developed to estimate regression:

$$
Y_{i t}=\alpha_{0}+\beta I S O_{i t}+\gamma S I Z E_{i t}+\eta R A T E_{i t}+\theta D E G R E E_{i t}+\phi X_{i}+\varepsilon_{i t} \text { (1) }
$$

In this equation, the term $\mathrm{Y}$ is used to represent the innovation of the firm, ISO is the independent variable, SIZE, RATE and DEGREE are used to represent the firm size, profit rate and the degree of competition faced by the firm, and the term $\mathrm{X}_{\mathrm{i}}$ is used to represent the fixed dummy variable that accounts for the industry in which the firm belongs.

The chosen firms in the sample have made investments in innovation in any of the selected years. The variable ARD cannot assume a negative value; therefore, the method adopted for evaluation was the POLS model and the Tobit regression, which can easily forecast the size and probability of an investment in any given year. When using the DRD variable in the evaluation of R\&D innovation, the Probit and POLS models were used. The Probit model is commonly used by researchers for binary regressions (Bu et al., 2020). The impact of government-imposed ERs was calculated and compared using the analytics on voluntary regulations. Moreover, a GMM estimation was performed to measure the robustness of the results.

\section{Results}

Before beginning the analysis and estimation, the variables were subjected to a correlation analysis in order to evaluate multicollinearity. The results of the correlation analysis are displayed in Table 1. The correlation coefficients of most of the variables lie in the moderate range, i.e. less than 0.4. Therefore, the problem of multicollinearity isn't found in the dataset.

\begin{tabular}{c|c|c|c|c|c|c|c|c}
\hline \multicolumn{9}{c}{ Table 1. Correlation analysis. } \\
\hline Variable & ARD & DRD & ISO & Size & Rate & Fierce & Low & High-tech \\
\hline ARD & 1 & & & & & & & \\
\hline DRD & 0.378 & 1 & & & & & & \\
\hline ISO & 0.045 & 0.12 & 1 & & & & & \\
\hline Size & 0.036 & 0.154 & 0.271 & 1 & & & & \\
\hline Rate & 0.028 & 0.053 & 0.045 & 0.082 & 1 & & & \\
\hline Fierce & 0.006 & 0.036 & 0.074 & 0.055 & 0.003 & 1 & & \\
\hline Low & 0.023 & 0.041 & 0.026 & 0.112 & 0.025 & 0.222 & 1 & \\
\hline Hightech & 0.070 & 0.095 & 0.066 & 0.106 & 0.021 & 0.02 & 0.003 & 1 \\
\hline
\end{tabular}

Table 2 displays the estimations for Equation 1. The POLS, Probit and Tobit models were used to evaluate the impact of the voluntary regulations on the innovation of the firm. Models 1 and 2 represent the estimations of the impact of the ISO certification on investments made for R\&D using the Tobit and the POLS model. The calculated coefficients for ISO in both models were 0.0366 and 0.222; they are both positive and significant at a level of five percent. These results indicate that the voluntary registration has a positive and significant impact on the innovation of the firms. Models 3 and 4 used the dummy variable DRD in order to evaluate the relationship between FI and the voluntary regulations. The estimations and evaluations for the assessment were calculated on the basis of the Probit and the POLS model and the coefficients for ISO were significant and positive. The coefficient values were 0.0873 and 1.502 and significant at the level of one percent. These results support the hypothesis (H1), which stated that the acceptance and implementation of VERs has a significant and positive effect on the overall innovation of a firm. The control variables were also evaluated in order to study the impact of the firm's characteristics on its level of innovation. The control variables of size and profit rate were found to be significant. The variable firm size was significant and positive in Models 2, 3 and 4, whereas the variable profit rate was found to be significant in Models 3 and 4 . These results indicate that larger firms have more exposure and a 
higher chance of performing well and being more profitable; moreover, the more profitable the firm is, the more it will be inclined to invest in R\&D activities. The coefficients for market competition were insignificant, which showed that there is no relation between innovation activities and the competition faced by firms. The coefficient for high technology was significant in Models 1 and 2, which showed that firms that are either equipped with technology or are operating in the technology industry are more likely to invest in innovation activities.

Table 2. Estimation of coefficients.

\begin{tabular}{|c|c|c|c|c|}
\hline Variable & POLS (1) & Tobit (2) & POLS (3) & Probit (4) \\
\hline \multirow[t]{2}{*}{ ISO } & $0.0366^{* *}$ & $0.222^{* * *}$ & $0.0873^{* * *}$ & $1.502^{* * *}$ \\
\hline & -0.0182 & -0.0929 & -0.031 & -0.285 \\
\hline \multirow[t]{2}{*}{ Size } & 0.00312 & $0.0708 * *$ & $0.0479^{* * * *}$ & $0.389^{* * *}$ \\
\hline & -0.00489 & -0.0329 & -0.00556 & -0.0934 \\
\hline \multirow[t]{2}{*}{ Rate } & 0.0116 & 0.34 & $0.156 * * *$ & $1.253^{*}$ \\
\hline & -0.0438 & -0.214 & -0.0481 & -0.682 \\
\hline \multirow[t]{2}{*}{ Fierce } & 0.000211 & 0.0838 & 0.0166 & 0.287 \\
\hline & -0.0143 & -0.107 & -0.0148 & -0.27 \\
\hline \multirow[t]{2}{*}{ Low } & 0.0517 & 0.862 & $0.139^{* * * *}$ & 2.242 \\
\hline & -0.052 & -0.613 & -0.0549 & -1.852 \\
\hline \multirow[t]{2}{*}{ High-tech } & $0.0576^{* * *}$ & 0.101 & $0.0552^{* *}$ & 0.185 \\
\hline & -0.0226 & -0.105 & -0.0247 & -0.338 \\
\hline R-squared & 0.021 & & 0.086 & \\
\hline
\end{tabular}

The firms were subject to regulations imposed by the government, irrespective of whether they implement the voluntary regulations or not, so the analysis also considers the impact of government-imposed regulations in order to see which has a more significant impact on the innovation of the firm. Table 3 presents the results of the analysis. For the purpose of evaluating the impact of government-imposed regulations, a new variable was introduced into the models. The variable ER was used to assess the severity of the government regulations imposed to improve environmental efficiency. The variable ER has been defined as the number of investigations made by the government per year. Models 5 and 6 evaluate the impact of government regulations and voluntary regulations through a consideration of the dependent variable ARD; while in Models 7 and 8, the dummy variable DRD is used.

\begin{tabular}{|c|c|c|c|c|}
\hline Variable & POLS (5) & Tobit (6) & POLS (7) & Probit (8) \\
\hline \multirow[t]{2}{*}{ ISO } & $0.0386^{* * *}$ & $0.227^{*} *$ * & $0.102^{* * * *}$ & $1.583^{*} * * *$ \\
\hline & -0.0189 & -0.0949 & -0.0229 & -0.313 \\
\hline \multirow[t]{2}{*}{ Size } & 0.0032 & $0.0751^{* *} *$ & 0.0471 **** & 0.391 **** \\
\hline & -0.0052 & -0.0345 & -0.00572 & -0.0958 \\
\hline \multirow[t]{2}{*}{ Rate } & 0.0211 & $0.428^{*}$ & $0.177^{*} * * *$ & $1.595^{* * *}$ \\
\hline & -0.0467 & -0.234 & -0.0524 & -0.771 \\
\hline \multirow[t]{2}{*}{ Fierce } & 0.00218 & 0.0287 & 0.00038 & 0.0659 \\
\hline & -0.0152 & -0.12 & -0.0179 & -0.308 \\
\hline \multirow[t]{2}{*}{ Low } & 0.0567 & 0.7 & O.174**** & 2.446 \\
\hline & -0.0523 & -0.598 & -0.0575 & -1.776 \\
\hline \multirow[t]{2}{*}{ High-tech } & $0.0825^{* * * *}$ & 0.117 & 0.0827 ***** & 0.0268 \\
\hline & -0.0225 & -0.113 & -0.0248 & -0.372 \\
\hline \multirow[t]{2}{*}{ ER } & 0.000234 & 0.000111 & 0.000721 & 0.0122 \\
\hline & -0.000599 & -0.00377 & -0.000646 & -0.0276 \\
\hline \multirow[t]{2}{*}{ Constant } & 0.042 & $2.226^{* * * *}$ & $0.225^{* * * *}$ & $9.328^{* * * *}$ \\
\hline & -0.0339 & -0.224 & -0.0372 & -0.631 \\
\hline R-squared & 0.027 & & 0.097 & \\
\hline
\end{tabular}

Table 4. GMM estimations

\begin{tabular}{|c|c|c|}
\hline Variable & GMM (9) & GMM (10) \\
\hline \multirow[t]{2}{*}{ ISO } & $0.0435 * *$ & 0.121 **** \\
\hline & -0.0223 & -0.0232 \\
\hline \multirow[t]{2}{*}{ Size } & 0.00253 & $0.0446^{* * * *}$ \\
\hline & -0.00501 & -0.00553 \\
\hline \multirow[t]{2}{*}{ Rate } & 0.00935 & 0.162 **** \\
\hline & -0.0449 & -0.059 \\
\hline \multirow[t]{2}{*}{ Fierce } & 0.000474 & 0.0172 \\
\hline & -0.0146 & -0.0168 \\
\hline \multirow[t]{2}{*}{ Low } & 0.0513 & $0.156^{* * * *}$ \\
\hline & -0.052 & -0.0567 \\
\hline \multirow[t]{2}{*}{ High-tech } & 0.0574 ***** & $0.0553^{* *}$ \\
\hline & -0.0226 & -0.0246 \\
\hline \multirow[t]{2}{*}{ Constant } & 0.0352 & 0.217 ***** \\
\hline & -0.0332 & -0.0331 \\
\hline R-squared & 0.022 & 0.077 \\
\hline AR 1 & 0.56 & 0.91 \\
\hline $\mathrm{AR} 2$ & 0.73 & 0.23 \\
\hline SARGAN test & 0.66 & 0.44 \\
\hline
\end{tabular}

The ISO 14000 certification was found to be significant in all four models, which is in line with the estimations displayed in Table 2. However, the effects of governmental environment regulations are insignificant in all four 
models, demonstrating that the implementation of VERs have a greater impact on the innovation performance of firms. The effects of the control variables are the same as evaluated in Table 3.

The GMM estimation was performed to consider the effects of VERs in instances when they are lagged. The results are presented in Table 4. The lagged phase one data for the ISO 14000 certification was used. Models 9 and 10 report significant values in the coefficients of voluntary regulations. The values are positive and significant, which indicates the robustness of the results when a lagged effect is considered to be present. In order to evaluate the robustness of the model, the serial correlation was analyzed using autoregressive tests, and the SARGAN test was used to evaluate the over-estimation or inclusion of extra variables in the model. It can be seen from the results that such an issue does not prevail and, therefore, the results are deemed to be efficient.

\section{Discussion and Conclusion}

Recently, studies evaluating the effects of voluntary, government-imposed, and supervised ERs and their impact on performance indicators such as profitability, environmental performance, and innovative activities have been increasing. This discussion is developing because of the global issue of increasing levels of pollution. The concentration of pollution in China is significant due to the presence of heavy industries; as a result, literature evaluating ERs has increased (Bigliardi, Bertolini, Doran, \& Ryan, 2012; Li, Tang, \& Zhang, 2020; Tang, 2015; You et al., 2019). There is a varying evidence relating to the impact of ERs on innovation activities in Chinese firms. This study explored the relationship between VERs and the innovation of firms using data on the implementation and application of the ISO 14000 certification. The results of the study show that the implementation of VERs have a significant impact on the innovation of firms. The study by Liu et al. (2018) evaluated the impact of different ERs on the consumption of energy using a least squares method. The study found that supervised and economical regulations reduce consumption patterns of energy. The study by Fang, Gao, and Lai (2020) evaluated the impact of ERs on organizational innovation in China. This study evaluated the impact of supervised regulations from the government on the innovation of firms. In order to do so, the researchers analyzed government-monitored firms to understand the impact of FI in china. It was found that China's distinctive and monitored program significantly influenced FI. Moreover, financial constraints, financial conditions, and firm size were found to be important characteristics in the evaluation of the performance of the firms. Implementing effective ERs in firms is one way of considering global ecological impacts through improved green practices. Liu, Xie, and ealth (2020) evaluated the impact of ERs and their impact on the efficiency and competitiveness of the domestic Chinese manufacturing sector. The competitiveness of export functions and value-added products were also considered. The researchers used the Porter hypothesis to evaluate the impact of the regulations on the effectiveness of the export sector. The results of this study point to the presence of an internal heterogeneity in the industry. Moreover, technological competitiveness and political regulations were found to have a significant impact on the relationship between innovation and regulation.

The objective of the present study was to evaluate the impact of VERs on FI. For this purpose, POLS, Probit, and Tobit models were used to evaluate the impact of VERs on the innovation of the firms. The study used the adoption or application of the ISO 14000 to measure voluntary regulations, and a dichotomous dependent variable was designed. The results of the estimations showed a clear and significant impact of VERs on the stimulation of innovation activities in Chinese firms. Moreover, in order to validate the findings, the study introduced government-imposed regulations and VERs into the same model. The results indicate that the impact of the voluntary regulations is more significant, putting the firms in a more likely position to ensure innovative activities. Furthermore, the presence of lagged variables was accounted for, as the GMM estimation provided significant results on voluntary regulations and proved the robustness of the results.

\section{Policy Implication and Limitations}

The findings of the study emphasize the importance of VERs on the innovation of firms. Moreover, policy procedures in developing countries need to focus on the importance of the voluntary adoption of ERs so that emissions can be reduced, and innovation can be stimulated. The limitations of the study are that it focuses on general innovation indicators, due to limited data. Thus, future researchers should focus on evaluating innovation using direct and more robust indicators.

\section{References}

Ambec, S., \& Barla, P. (2002). A theoretical foundation of the porter hypothesis. Economics Letters, 75(3), 355-360.Available at: https://doi.org/10.1016/s0165-1765(02)00005-8.

Ambec, S., Cohen, M. A., Elgie, S., \& Lanoie, P. (2013). The porter hypothesis at 20: Can environmental regulation enhance innovation and competitiveness? Review of Environmental Economics and Policy, 7(1), 2-22.Available at: https://doi.org/10.1093/reep/res016.

Ball, C., Burt, G., De Vries, F., \& MacEachern, E. (2018). How environmental protection agencies can promote eco-innovation: The prospect of voluntary reciprocal legitimacy. Technological Forecasting and Social Change, 129, 242-253.Available at: https://doi.org/10.1016/j.techfore.2017.11.004.

Becheikh, N., Landry, R., \& Amara, N. (2006). Lessons from innovation empirical studies in the manufacturing sector: A systematic review of the literature from 1993-2003. Technovation, 26(5-6), 644-664.Available at: https://doi.org/10.1016/j.technovation.2005.06.016.

Bigliardi, B., Bertolini, M., Doran, J., \& Ryan, G. J. E. J. o. I. M. (2012). Regulation and firm perception, eco-innovation and firm performance. European Journal of Innovation Management, 15(4), 421-441.Available at: https://doi.org/10.1108/14601061211272367.

Bu, M., Qiao, Z., \& Liu, B. (2020). Voluntary environmental regulation and firm innovation in China. Economic Modelling, 89(C), 1018.Available at: https://doi.org/10.1016/j.econmod.2019.12.020.

Cohen, M. A., \& Tubb, A. (2018). The impact of environmental regulation on firm and country competitiveness: A meta-analysis of the porter hypothesis. Journal of the Association of Environmental and Resource Economists, 5(2), 371-399.Available at: https://doi.org/10.1086/695613.

Demirel, P., Iatridis, K., \& Kesidou, E. (2018). The impact of regulatory complexity upon self-regulation: Evidence from the adoption and certification of environmental management systems. Journal of Environmental Management, 207, 80-91.Available at: https://doi.org/10.1016/j.jenvman.2017.11.019. 
Fang, J., Liu, C., \& Gao, C. (2019). The impact of environmental regulation on firm exports: Evidence from environmental information disclosure policy in China. Environmental Science and Pollution Research, 26(36), 37101-37113.Available at: https://doi.org/10.1007/s1 1356-019-06807-2.

Fang, J., Gao, C., \& Lai, M. (2020). Environmental regulation and firm innovation: Evidence from national specially monitored firms program in China. Journal of Cleaner Production, 271, 122599.Available at: https://doi.org/10.1016/j.jclepro.2020.122599.

Feng, Z., \& Chen, W. (2018). Environmental regulation, green innovation, and industrial green development: An empirical analy sis based on the spatial durbin model. Sustainability, 1O(1), 223.Available at: https://doi.org/10.3390/su10010223.

Guohui, S., \& Yunfeng, L. (2012). The effect of reinforcing the concept of circular economy in west china environmental protection and economic development. Procedia Environmental Sciences, 12, 785-792.Available at: https://doi.org/10.1016/j.proenv.2012.01.349.

Holz, C. A. (2014). The quality of China's GDP statistics. China Economic Revier, 30, 309-338.Available at: https://doi.org/10.1016/j.chieco.2014.06.009.

Jiang, Z., Wang, Z., \& Li, Z. (2018). The effect of mandatory environmental regulation on innovation performance: Evidence from China. Journal of Cleaner Production, 203, 482-491.Available at: https://doi.org/10.1016/j.jclepro.2018.08.078.

Lanoie, P., Patry, M., \& Lajeunesse, R. (2008). Environmental regulation and productivity: Testing the porter hypothesis. Journal of Productivity Analysis, 30(2), 121-128.Available at: https://doi.org/10.1007/s11123-008-0108-4.

Li, D., Tang, F., \& Zhang, L. (2020). Differential effects of voluntary environmental programs and mandatory regulations on corporate green innovation. Natural Hazards, 1-20.Available at: https://doi.org/10.1007/s 11069-020-04137-y.

Liu, Y., Li, Z., \& Yin, X. (2018). Environmental regulation, technological innovation and energy consumption---a cross-region analysis in China. Journal of Cleaner Production, 203, 885-897.Available at: https://doi.org/10.1016/j.jclepro.2018.08.277.

Liu, J., Xie, J. J. I. J. o. E. R., \& ealth, P. (2020). Environmental regulation, technological innovation, and export competitiveness: An empirical study based on China's Manufacturing Industry, 17(4), 1427.Available at: https://doi.org/10.3390/ijerph 17041427.

Murty, M. N., \& Kumar, S. (2003). Win-win opportunities and environmental regulation: Testing of porter hypothesis for Indian manufacturing industries. Journal of Environmental Management, 67(2), 139-144.Available at: https://doi.org/10.1016/s03014797(02)00203-7.

Naranjo-Gil, D. (2009). The influence of environmental and organizational factors on innovation adoptions: Consequences for performance in public sector organizations. Technovation, 29(12), 810-818.Available at: https://doi.org/10.1016/j.technovation.2009.07.003.

Pan, X., Ai, B., Li, C., Pan, X., \& Yan, Y. (2019). Dynamic relationship among environmental regulation, technological innovation and energy efficiency based on large scale provincial panel data in China. Technological Forecasting and Social Change, 144, 428-435.Available at: https://doi.org/10.1016/j.techfore.2017.12.012.

Ren, S., Li, X., Yuan, B., Li, D., \& Chen, X. (2018). The effects of three types of environmental regulation on eco-efficiency: A cross-region analysis in China. Journal of Cleaner Production, 173, 245-255.Available at: https://doi.org/10.1016/j.jclepro.2016.08.113.

Rennings, K., \& Rammer, C. (2011). The impact of regulation-driven environmental innovation on innovation success and firm performance. Industry and Innovation, 1 8(03), 255-283.Available at: https://doi.org/10.1080/13662716.2011.561027.

Rexhäuser, S., \& Rammer, C. (2014). Environmental innovations and firm profitability: Unmasking the porter hypothesis. Environmental and Resource Economics, 57(1), 145-167.

Rubashkina, Y., Galeotti, M., \& Verdolini, E. (2015). Environmental regulation and competitiveness: Empirical evidence on the porter hypothesis from European manufacturing sectors. Energy Policy, 83, 288-300.Available at: https://doi.org/10.1016/j.enpol.2015.02.014.

SC Filho, J. F., Romano, P. N., De Almeida, J. M., \& Sousa-Aguiar, E. F. (2019). Critical catalytic routes: From the conventional bioethanol production model toward the integrated biorefinery concept. Current Opinion in Green and Sustainable Chemistry, 20, 33-38.Available at: https://doi.org/10.1016/j.cogsc.2019.09.002.

Soto-Acosta, P., Popa, S., \& Palacios-Marqués, D. (2017). Social web knowledge sharing and innovation performance in knowledge-intensive manufacturing SMEs. The Journal of Technology Transfer, 42(2), 425-440.Available at: https://doi.org/10.1007/s 10961-016-9498-z.

Stock, G. N., Greis, N. P., \& Fischer, W. A. (2002). Firm size and dynamic technological innovation. Technovation, 22(9), 537-549.Available at: https://doi.org/10.1016/s0166-4972(01)00061-x.

Tang, R. (2015). Environmental regulation and firm innovation: Evidence from China: Retrieved from: http://www.ualberta.ca/econphd/Ruotao Tang JMP.pdf.

Ukpabio, M., Siyanbola, W. J. I. J. o. I. R., \& Studies, A. (2017). Technological innovation and performance of manufacturing firms in Nigeria. $4(11), 10-19$.

Verdu, A. J., Tamayo, I., \& Ruiz-Moreno, A. (2012). The moderating effect of environmental uncertainty on the relationship between real options and technological innovation in high-tech firms. Technovation, 32(9-10), 579-590.Available at: https://doi.org/10.1016/j.technovation.2012.06.001.

Wang, C., Wu, J., \& Zhang, B. (2018). Environmental regulation, emissions and productivity: Evidence from Chinese COD-emitting manufacturers. Journal of Environmental Economics and Management, 92, 54-73.Available at: https://doi.org/10.1016/j.jeem.2018.08.004.

Wang, Y., \& Shen, N. (2016). Environmental regulation and environmental productivity: The case of China. Renewable and Sustainable Energy Reviews, 62, 758-766.Available at: https://doi.org/10.1016/j.rser.2016.05.048.

Wibisana, A., \& Dewaranu, T. (2017). Environmental damage and liability in Indonesia: Fancy words under conventional wisdom law and justice in a globalized world (pp. 221-228): Routledge.

You, D., Zhang, Y., \& Yuan, B. (2019). Environmental regulation and firm eco-innovation: Evidence of moderating effects of fiscal decentralization and political competition from listed Chinese industrial companies. Journal of Cleaner Production, 207, 10721083.Available at: https://doi.org/10.1016/j.jclepro.2018.10.106.

Zehir, C., \& Özsahin, M. (2008). A field research on the relationship between strategic decision-making speed and innovation performance in the case of Turkish large-scale firms. Management Decision, 46(5), 709-724.Available at: https://doi.org/10.1108/00251740810873473.

Zehir, C., \& Özşahin, M. (2008). A field research on the relationship between strategic decision-making speed and innovation performance in the case of Turkish large-scale firms. Management Decision, 46(5), 709-724.

Zhao, X., Zhao, Y., Zeng, S., \& Zhang, S. (2015). Corporate behavior and competitiveness: Impact of environmental regulation on Chinese firms. Journal of Cleaner Production, 86, 311-322.Available at: https://doi.org/10.1016/j.jclepro.2014.08.074.

Zhou, X., \& Feng, C. (2017). The impact of environmental regulation on fossil energy consumption in China: Direct and indirect effects. Journal of Cleaner Production, 4(142), 3174-3183.Available at: https://doi.org/10.1016/j.jclepro.2016.10.152.

Zhuge, L., Freeman, R. B., \& Higgins, M. T. (2020). Regulation and innovation: Examining outcomes in Chinese pollution control policy areas. Economic Modelling, 89(C), 19-31.Available at: https://doi.org/10.1016/j.econmod.2019.09.041. 